\title{
Managing the trade-off implications of global supply
}

Corresponding author: Roy Stratton, Nottingham Business School, Nottingham Trent University, Nottingham NG1 4BU (E-mail: roy.stratton@ntu.ac.uk) (Tel: +44 115848 2715) (Fax: +44 115848 6512)

Second author

Roger D.H. Warburton, Metrapolitan College, Boston University, Ma 02115 USA (E-mail: rwarb@bu.edu)

\begin{abstract}
The cost versus response trade-off is a growing logistics issue due to many markets being increasingly characterized by demand uncertainty and shorter product life cycles. This is exacerbated further with supply increasingly moving to low cost global sources. However, the poor response implications of global supply are often not addressed or even acknowledged when undertaking such decisions. Consequently, various practical approaches to minimising, postponing or otherwise managing the impact of the demand uncertainty are often only adopted retrospectively. Even though such generic solutions are documented through case examples we lack effective tools and concepts to support the proactive identification and resolution of such trade-offs. This paper reports on case-based theory building research, involving three cases from the UK and USA used in developing a conceptual model with associated tools, in support of such a process.
\end{abstract}

\section{Introduction}


Addressing the strategic as well as the cost implications of functional decisions continues to be elusive. In the past the resulting misalignment was commonly associated with the incremental nature of such change (Hill, 1998), but this does not fully explain the mismatch that commonly results from outsourcing decisions. Research suggests that such decisions often lack a holistic perspective (Baines, 2003) resulting in a sub-optimal cost focus. The growth in global sourcing, however, is increasingly encroaching on markets characterized by shorter product life cycles and increasing demand uncertainty. Global supply from low cost sources is, therefore, increasingly prone to aggravating the cost versus response trade-off (Nair and Closs, 2006) - a problem that is now widely cited, particularly in the apparel industry (Lowson, 2003).

Practical strategies to address such supply chain misalignments have been widely reported over the years, such as Bennetton, Sports Obermeyer (Fisher et al., 1994), Hewlett Packard (Feitzinger and Lee, 1997) and more recently Zara. However, the tendency to think functionally rather than holistically persists (Fisher, 1997; Fisher, 2000; Ferdows, 2003; Geary, Disney and Towill, 2006)

This paper seeks to explain the growing significance of the cost versus response trade-off as well as presenting a conceptual approach to managing such (trade-offs and concepts in support of strategic decision making) trade-offs in the context of the

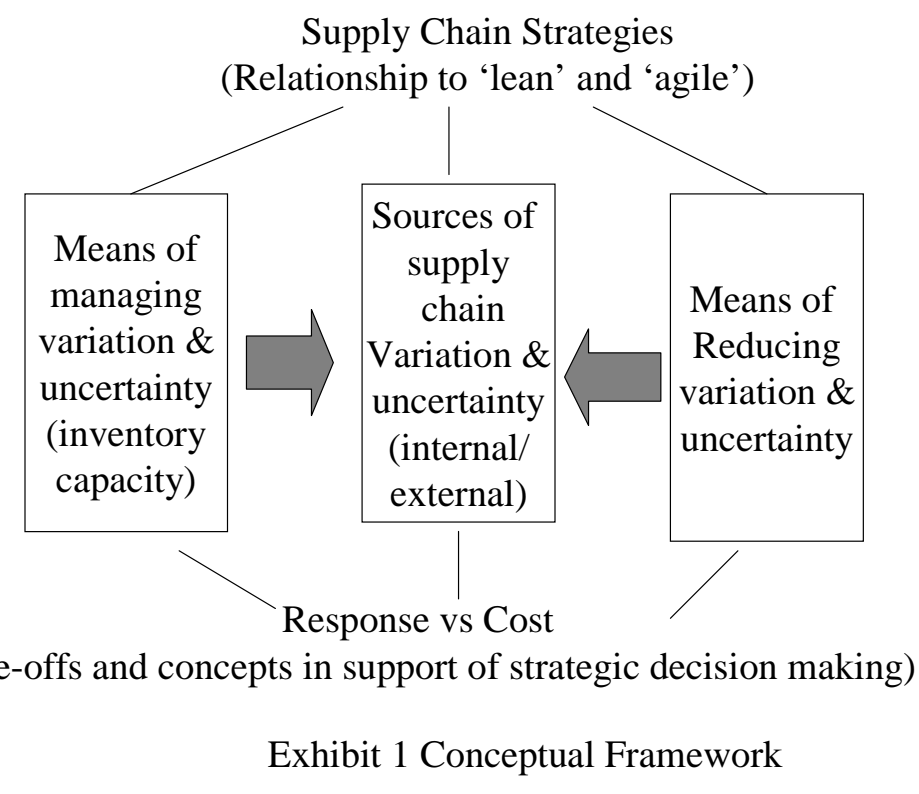


supply chain. Three case studies, associated with outsourcing, are subsequently analysed in relation to this approach.

\section{$2 \quad$ Research Programme Design}

This paper is part of a wider research project aimed at exploring strategies and supporting concepts used to improve the level of stability within a supply chain. The conceptual framework is derived from the initial secondary research (see Exhibit 1) and from this some key questions were derived:

- How does internal and external system variation and uncertainty impact on a supply chain?

- How and why do different strategies limit such variation and uncertainty?

- How and why does the trade-off concept support the strategy development process?

- How can a company use investments in inventory and capacity to provide greater stability in the internal and external phases of a delivery system?

In choosing case studies that explicitly exhibit the instability associated with the cost versus delivery speed trade-off, a number of companies involved in realigning their strategies following outsourcing decisions were selected. This resulted in a further question - under what conditions does local rather than strategic decision-making tend to predominate? This paper addresses these questions in relation to the three case studies associated with outsourcing.

The case-based research method was adopted, given the explanatory nature of the research questions being posed (Yin, 1994). Cases were chosen and administered in accordance with replication logic (Eisenhardt, 1989). The unit of analysis was the company and data was collected with a research protocol using multiple sources of evidence. The data collection method included 
plant observation, semi-structured interviews, archival records and documents, with due attention being given to triangulation and subsequent analysis (Miles and Huberman, 1994).

\section{Secondary research used in the derivation of the conceptual model}

The research has identified three conceptual approaches to managing trade-offs in supply chains, with particular reference to the cost versus delivery speed trade-off. This review of previous research and practice is structured to reflect the derived model.

\section{The trade-off concept and continuous improvement}

The emergence of management science in the early part of the last century was functionally structured and resulted in local optimization centred on cost. In this way the level of inspection and the size of batches were determined via cost models that provided a means of optimizing the conflicting

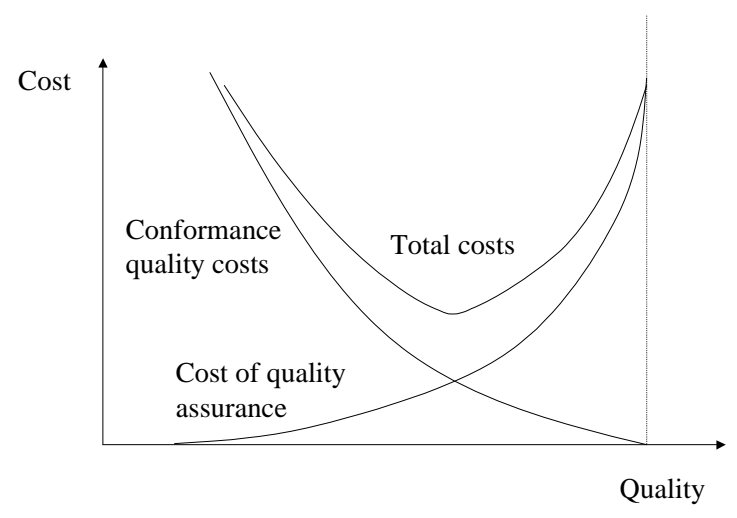

Exhibit 2 Traditional Conformance Quality Cost Model requirements (see Exhibit 2 and 3).

By the 1960s the need for organisations to be aligned to specific market requirements was identified (Burns and Stalker, 1961) and Skinner (1969) exposed the strategic need to align the operations management sub-functions to satisfy market requirements other than price. This work was further developed (Hayes and Wheelwright, 1979; Hill, 1985) with concepts to help distinguish the different market characteristics and classic process alignments. 
In Japan, however, they had already embarked on a different approach. Deming's Japanese lecture series from the 1950s had created an awareness of the strategic importance of not just realigning the strategic choices but reducing special and common causes of variation in an organization and thereby attacking the conformance quality-cost trade-off at source (1982). Deming's work was considered to be central to Toyota's success and Ohno (1988) applied this thinking to production flow and

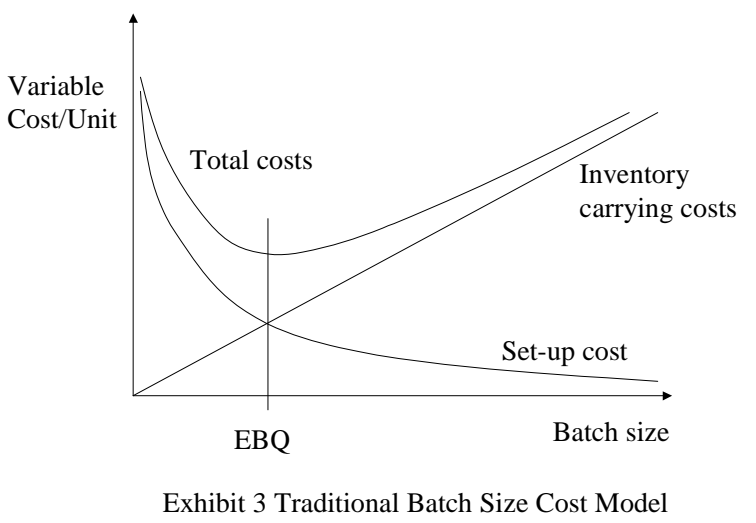
similarly challenged the waste associated with poor process reliability and the process inflexibility associated with long set-up times. Hence, it is not surprising that some authors were questioning the merits of the 'either or' mentality associated with the trade-off concept (Schonberger, 1982). Ferdows and De Meyer (1990) used empirical research in support of 'a new theory' that integrated these findings and argued that the trade-off concept, although still relevant to strategic decision-making, needed to acknowledge the opportunity to systematically reduce the cause of the trade-offs. Their sand cone model suggested a natural sequence to improvement they referred to as cumulative capabilities, which starts with quality, followed by dependability, flexibility and finally cost. This extended earlier work by Nakane (1986), which emphasised the importance of improving quality and dependability before imposing demands for increased flexibility on a delivery system. Ferdows and Meyer's study led to the conclusion that focusing on quality reduces the sources of variation in the system, which improves efficiency and reduces cost, whereas, focusing on costs does not result in a corresponding improvement in quality. These developments stress the importance of understanding how the order of priority, particularly 
concerning cost, impacts trade-offs and although conformance quality versus cost is still listed as a trade-off by some industrialists it is now commonly acknowledged to be a 'perceived' rather than 'real' trade-off (Da Silveira and Slack, 2001). Mapes et al. (1997) conducted survey research that also acknowledges the fact that good performance on one measure leads to good performance on other measures. Their work stressed the need to eliminate uncertainty and unreliability as well as waste, arguing that much surplus inventory, labour and capital equipment is a consequence of uncertainty and unreliability. Slack’s (1998) generic trade-off approach similarly identifies the role of flexibility in reducing the impact of variation and uncertainty and therefore the trade-off implications.

\subsubsection{Developing the trade-off concept}

Schmenner and Swink (1998) in developing this conceptually have proposed a 'theory of performance frontiers' distinguishing between an asset and an operating frontier. Exhibit 4 illustrates this concept in relation

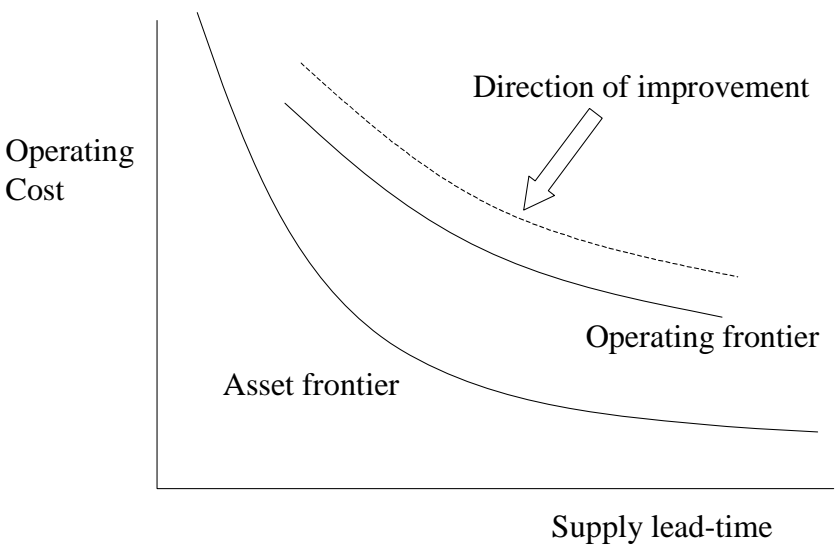

Exhibit 4 Illustrative trade-off curve showing the asset and operating frontiers.

to the operating cost versus supply lead-time trade-off. An asset frontier defines the performance trade-off under ideal operating conditions, so defining the performance limits of the physical assets. Whereas, an operating frontier acknowledges the limitations of the infrastructure system variables (such as quality, process reliability and set-up times) associated with policies. Therefore, in line with the above, simultaneously improving the system performance on all fronts is possible and under these circumstances the operating frontier shifts closer to the limiting 
frontier of the current assets. Vastag (2000) usefully adds to this work by stressing the significance of the operating frontier as opposed to the asset frontier in gaining competitive advantage. He relates this to the tacit performance improvements associated with Toyota that have been so difficult to replicate (Alder et al., 1999).

Goldratt (1990) similarly argues, in what is now commonly known as the 'theory of constraints', that the performance of a system is rarely constrained by resources and the corresponding asset frontier but by what he refers to as policy constraints. His work stresses the importance of challenging the assumptions underpinning such policies that give rise to the trade-off models typified in Exhibits 1 and 2. The cost focus of these models does not acknowledge different order winning criteria and encourages a sub-optimal rather than strategic perspective, consequently giving rise to policies that sustain the associated wasteful variation, as illustrated by the concepts such as acceptable quality levels and economic batch quantities.

Whereas Deming and later Ohno universally targeted wasteful variation associated with nonconformance, reliability and inflexibility under the umbrella of continuous improvement, Goldratt developed the use of the trade-off concept to focus strategic improvement. In this way he found a means of systematically exposing and challenging the policies that limited (constrained) the throughput of the system, akin to shifting the operating frontier associated with specific products and markets. His contention was that improving the systems throughput, unlike cost reduction, was an inherently focused activity and very few policies or resources constrained a system at one time.

\subsubsection{Systematically expressing and resolving trade-offs}


In an attempt to illustrate how the trade-off concept may be used to focus improvement, the batch size model has been presented (Exhibit 5) in such a way that the policies and associated thinking underpinning the model may be challenged systematically. This is in the form of an Evaporating Cloud Diagram (Goldratt, 1990) otherwise known as a Conflict Resolution Diagram (CRD) (Scheinkopf, 1999).

Exhibit 5 represents the logic of the traditional batch optimization diagram (Exhibit 3), where requirements $\mathrm{B}$ and $\mathrm{C}$ are necessary (but not

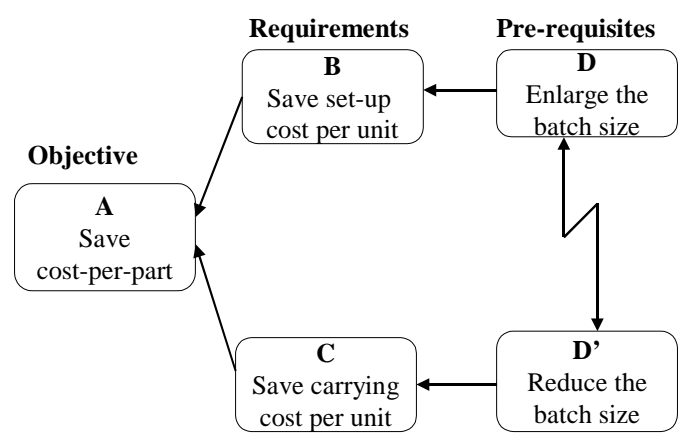

Exhibit 5 Traditional batch size trade-off model in the form of a conflict resolution diagram. sufficient) to achieve the objective A. Similarly the prerequisites D and D' are necessary (but not sufficient) to achieve the requirements at B and C, respectively. The pre-requisite requirements are normally shown as opposites to make the contradiction as explicit as possible, so enabling the logic underpinning it to be challenged. In TOC terms, the Cloud is evaporated (i.e. the problem is solved) if one of the assumptions embodied in an arrow can in some way be invalidated. By way of example, in Japan, the Toyota Production System challenged the assumptions underpinning the arrow B-D (Shingo, 1990), which states that large batches are a necessary prerequisite for reducing set-up costs. Whereas, in the West the arrow $\mathrm{AB}$ was challenged when the associated cost accounting assumptions were challenged in the 1980s (Kaplan, 1984). Goldratt (1983) more explicitly stressed the fallacy of using the inherent spare capacity in batch processing to increase excess inventory rather than shortening lead-times through increasing the number of setups. However, this wholesale assault on this cost model does not mean that trade-offs disappear but it 
does call for a rewrite of the diagram to define the strategic as opposed to cost trade-offs. This will be developed further in the next section.

\subsection{Investment choice: managing variation}

The above research and practice stresses the importance of reducing the sources of variation and uncertainty and highlights how policies embodied in sub-functional cost models have and, in many cases, continue to constrain the operating frontiers. This section considers the parallel need to manage as well as reduce variation in reconciling trade-offs and specifically looks at the strategic role of inventory and capacity in achieving this.

\subsubsection{The role of inventory and capacity in managing variation}

Skinner (1969) advocated making investment choices that were geared to the market or what Hill (1985; 2005) calls order winning and qualifying criteria. In this way investments suited to high volume low variety manufacture would typically compete on price with high levels of capacity utilization and low levels of WIP inventory. Alternatively, low volume high variety products, typically competing on delivery speed, would demand more responsive capacity and/or inventory to meet the inherent product variation and demand uncertainty that needs to be managed.

Supply chains may be protected from the disruptive nature of variation and uncertainty by using inventory or capacity to protect flow. However, the perception that an idle resource is a waste has resulted in the predominant use of inventory in the design of supply chains. 
Some authors have usefully structured the use of these factors in helping to manage uncertainty. For example, Newman et al. (1993) address the need to deal with uncertainties in manufacturing by linking flexibility at the macro and micro level to buffering through capacity, inventory and extended lead-times [order backlogs] in the form of a dynamic equilibrium model. They emphasise the trade-off choices of investing in capacity or inventory to protect flow. Correa (1994) links uncertainty and variation to the concepts of flexibility and its role in relieving associated trade-offs. Caputo (1996) explores the role of capacity and inventory buffers being used in combination and identifies many forms of capacity and inventory buffers, advocating that when effectively planned they do not necessarily result in hiding problems.

Fisher et al. (1997) stress the importance of 'reactive capacity' in configuring a supply chain to address constraints and illustrate this by challenging the concept of minimum lot size policies. The planned use of reactive capacity is evident in Goldratt's (1984) early work on the role of bottleneck resources in the management of delivery systems. Batch-processing environments have very few bottlenecks (resources constraints), however, the inherent spare capacity in such processes is not effectively utilised to enable flow (Conway et al., 1988) as cost models and local efficiency measures typically drive the operational decisions, as already discussed.

The Drum-Buffer-Rope planning and control system (Blackstone and Cox, 2002) is based on the selective use of capacity and inventory to protect flow in a delivery system and the

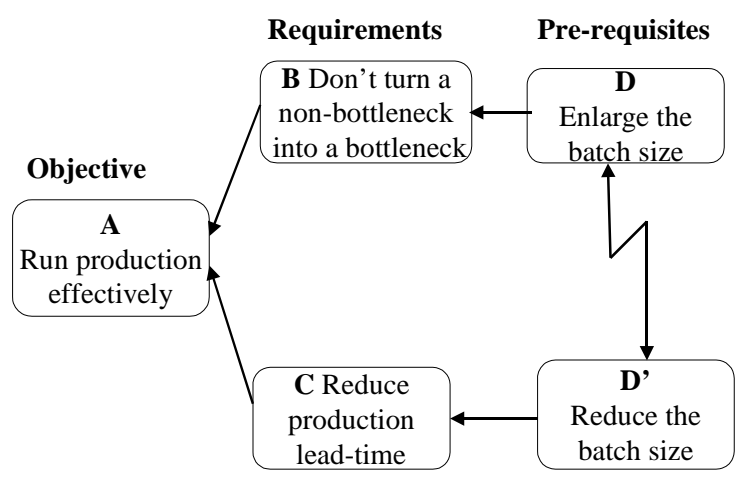

Exhibit 6 Batch Size CRD in the 'Throughput World' Source: Goldratt, 1996 
inventory buffers are then systematically managed to identify and target the sources of disruption. By this means protective inventory may be systematically reduced as with 'enforced problem solving'/ kaizen but unlike lean, the system acknowledges the explicit use of capacity on most resources to protect the flow from the inherent variation.

With this improved understanding of the role of capacity and inventory together with the existence of bottleneck resources, the batch size conflict (Exhibit 6) does not disappear but operates at a higher level, or as Schmenner might put it, the operating frontier is closer to the asset frontier. In this way the batch size is no longer fixed but varies depending on the availability of capacity, a common feature of Advanced Planning and Scheduling (APS) systems.

In Exhibit 6, requirement $\mathrm{C}$ reflects the drive to lower inventory, which is achieved through reducing the batch size. Whereas requirement B reflects the primary need to ensure sufficient capacity is available, which drives the need to enlarging the batch size and so reduce the capacity absorbed by set-ups.

\subsubsection{Interpreting lean and agile supply}

The agile-lean supply debate (MasonJones et al., 2000) has helped to highlight the growing importance of managing capacity to enable flow in a volatile market. Exhibit 7 serves to

illustrate the fact that variation and uncertainty associated with the product
Distinguishing attributes

Typical product Market place demand Product variety Product life cycle Manufacturing task Delivery penalties Purchasing policy Information enrichment

$\begin{array}{ll}\text { Lean supply } & \text { Agile supply } \\ \text { Commodities } & \text { Fashion goods } \\ \text { Stable } & \text { Unstable } \\ \text { Low } & \text { High } \\ \text { Long } & \text { Short } \\ \text { Low cost } & \text { Delivery Speed } \\ \text { Long term contractual } & \text { Loss of order } \\ \text { Product specific } & \text { Assign capacity } \\ \text { Desirable } & \text { Important }\end{array}$

Exhibit 7

Comparison of lean supply with agile supply: the distinguishing attributes Based on: Mason-Jones et al., 2000 (modified) 
and particularly demand, distinguishes lean from agile supply. Lean supply is associated with level production scheduling and the use of finished inventory to decouple fluctuations in demand. However, the uncertain demand and short life cycles of many innovative products cannot be effectively decoupled by inventory and, therefore, capacity is more actively utilised to protect delivery. Fisher (1997) has combined these two aspects of variation in what he refers to as functional and innovative products and the associated choice between designing an efficient or responsive supply chain. The efficient supply chain with minimal variation is naturally allied to lean, whereas the responsive supply chain is dependent on strategically located inventory and capacity to enable flow and is more closely allied to the concept of agile (Stratton and Warburton, 2003). Fisher provides practical guidelines on the need to avoid or reduce sources of variation and uncertainty in the first place, but stresses the need to acknowledge the uncertain nature of some product-market combinations and the corresponding need for responsive supply chains. This is achieved through the strategic location of responsive capacity and decoupling inventory to act as a hedge against variation and uncertainty.

It is important that the limitations of lean supply are understood if the strategic needs of volatile markets are to be acknowledged through appropriate investment. Variation and uncertainty in some delivery systems may be radically reduced but will never be eliminated and will therefore need to be managed through appropriate investment in

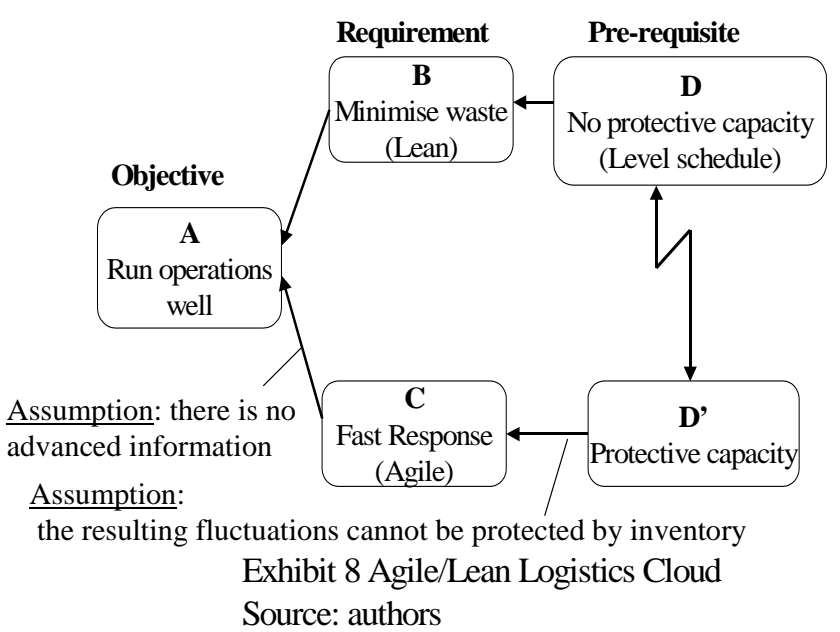
capacity and inventory. The form and location of this investment constitutes the associated trade- 
off investment choices identified by Skinner (1969). Exhibit 8 may be used to illustrate this tradeoff issue more explicitly. As before, the purpose behind this diagram is to focus attention on the strategic conflict, then challenge the underlying assumptions in relation to the specific products and markets at issue. The concept of protective capacity has been used to define the explicit nature of the conflict linking the dual requirements for fast response and low operating cost.

The assumptions identified in Exhibit 8 illustrate two commonly cited false assumptions. The logic underpinning arrow C-A assumes there is no more advanced information available that could be used to reduce the level of uncertainty; a fact readily challenged in the literature (Mason-Jones \& Towill, 1997) (Fisher, 2000). The assumption underpinning D'-C raises the possibility of holding inventory rather than capacity at a more stable position upstream, as in the use of decoupling inventory (Mason-Jones et al., 2000).

It is increasingly important that the role of capacity is considered in enabling flow as increasing demand uncertainty puts the holding of inventory increasingly at risk. Once the role of protective capacity is acknowledged means of economically focusing its provision can often be readily identified as illustrated in the cases that follow.

\subsection{Focused choices: separating out the conflict}

Having acknowledged the importance of reducing variation and uncertainty and the role of inventory and capacity in managing variation we return to the strategic concept of focus or what is referred to here as separating out the conflict.

The concept of focused manufacturing (Skinner, 1974) is a natural development from Skinner's seminal work (1969), which advocates splitting the manufacturing sub-functions up to form 'plants within plants', where the investment choices are aligned to meet specific market 
requirements. Fisher (1997) has extended this concept to supply chains, in identifying the match between efficient supply chains and functional products, and responsive supply chains and innovative products. Others have sought to subdivide the supply chain to separate out and minimize the impact of instability attributed to product variety and demand uncertainty, as in the concept of postponement (Van Hoek, 1998). Whereas Skinner's concept of focused manufacturing would typically separate out high volume from high variety products the associated supply chain equivalent encourages the upstream manufacture of the product to be standardized, thus postponing the introduction of product variety with the associated demand uncertainty. This strategy is also evident in what is now commonly called mass customization (Feitzinger and Lee, 1997). The concept of 'leagile' (Mason-Jones et al., 2000) is similarly related, but stresses the lean and the agile strategies reflected in the design of the product and its manufacture. In this way inventory is used to decouple the agile back end from the lean front end of the supply chain. In a similar way, supply of the stable base demand for a product may be separated out from potential demand surge by splitting early and late production (Gattorna and Walters, 1996).

\subsubsection{Developing Skinner's focused manufacturing analogy}

Skinner's concept of focus clearly has broader application, but the extension of the concept to supply chains has limited generalization to date and is often prescriptive in nature rather than encompassing design principles that could enable the concept to be more readily considered and creatively applied. It is interesting to note that Skinner's (1969) original argument for the 
relevance of the trade-off concept to the design of manufacturing systems was related to a mechanical engineering analogy.

'For instance, no one today can design a 500 passenger plane that can land on a carrier and also break the sound barrier. Much the same is true of manufacturing. The variables of cost, time, technological constraints, and customer satisfaction place limits on what management can do, force compromises, and demand an explicit recognition of a multitude of trade-offs and choices.'

However, this analogy can now be taken further as the mechanical engineering field has demonstrated how such trade-offs provide a focal point for applying innovative principles that support the resolution of such trade-offs.

The theory of inventive problem solving - TRIZ for short (A Russian acronym) - has therefore shed new light on this analogy. Genrich Altshuller developed TRIZ over several decades (Salamatov, 1999) but although widely applied in Russia it only appeared in the West recently. The theory resulted from the empirical analysis of over one million patents and the research determined that innovation was closely associated with the resolution of trade-off performance conflicts. Subsequent analysis identified that the same principles repeatedly appeared and were empirically related to certain types of contradiction or trade-off. The theory comprises several tools and principles, designed to support this process and is now commonly associated with systematic innovation. One of these approaches readily relates to operations design and is termed physical contradictions and separation principles. This solution system requires the trade-off contradiction to be defined explicitly, in a similar way to D-D' in cloud diagrams. In TRIZ this is termed a physical contradiction such as: fast versus slow; solid versus porous; moveable versus stationary and hot versus cold. This is, therefore, in the same form as used in the clouds cited 
earlier: i.e. large versus small batch and hold protective capacity versus don't hold protective capacity. Altshuller found that by defining the contradiction around one parameter with mutually exclusive states, the principles used to detect a solution could be more generic than other solution systems and consists of just four separation principles:

Separation of opposite requirements in space;

Separation of opposite requirements in time;

Separation within a whole and its parts;

Separation upon condition.

In engineering, where the conflict can be presented in this explicit form, these separation principles have proved to be very effective at stimulating the process of innovation with ideas that at least partially resolving the conflict. Similarly, these separation principles can be readily related to the concept of manufacturing focus and the more recent supply chain strategies identified above (Stratton and Warburton, 2003). It is therefore proposed that this concept of strategic separation provides a useful means of operationalising the creative application of the focusing concept in operations.

\section{$4 \quad$ Conceptual model}

This review identifies three conceptual approaches to supply chain improvement and demonstrates the link to previous work and the trade-off concept. These three approaches are reflected in the following conceptual model (Exhibit 9), which is subsequently used as a framework in the case analysis. 


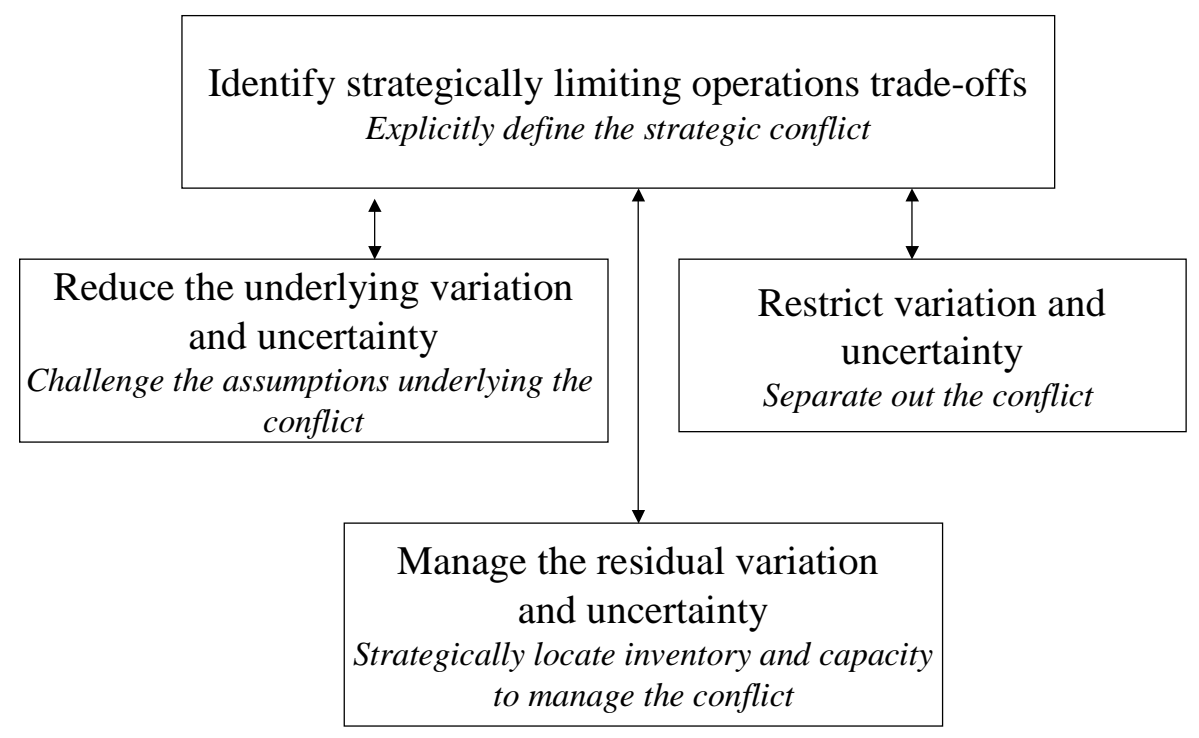

Exhibit 9 Proposed conceptual model for strategic supply chain improvement

\section{$5 \quad$ Case-based research evidence}

\subsection{Case A}

Case A, Griffin Manufacturing (Stratton and Warburton, 2003), is a US apparel manufacturer that moved into fashion athletic wear in recent years to avoid offshore competition. It provides technical support to customer design teams, imports fabric, cuts to size and manufactures garments. A few years ago their main corporate customer decided to move the manufacture of fashion products to its factory in Honduras which, until then, manufactured 'basic' non-fashion lines.

The low cost Honduran supply option, however, required long lead-times. Consequently, orders needed to be placed several months in advance and inventory was used to decouple supply from 
demand. For standard products, such as T-shirts, the long product life cycle meant the risk of obsolescence was low, but for the fashion items, the markdown and lost sales costs were significant and growing.

It was not long before the consequences of the outsourcing decision were felt. Although Honduras was much cheaper and in most cases could cope with the more technically demanding products, the supply lead-times required the buyers to forecast demand well in advance of the 16week sales season. Consequently, forecast errors commonly exceeded 25 per cent.

What eventually resulted was a partnership involving the both in-house and Griffin as suppliers. Early orders were placed on Honduras to a cautious forecast and at the start of the sales season demand was closely tracked so that the Griffin could fill any predicted shortages in the product range within the sales season.

Here the conflicting requirements of low cost and fast response were separated out in time and space with a mixed approach using inventory and capacity investment. The early season orders were satisfied by investing in inventory and the later season demand was satisfied by investing in responsive capacity that was used to match the demand of what proved to be the more popular lines. To maximise the product sales knowledge electronic point of sales data was used to improve the forecast accuracy once the sale season had commenced. To ensure the availability of Griffin's capacity the retailer guarantees a minimum of 15,000 to 20,000 garments per week. Consequently, if there was no top-up demand to be satisfied Griffin utilised its capacity by producing non-fashion goods for stock, that otherwise would have been produced in Honduras.

The decision to formalize the dual sourcing arrangement was the result of several failed attempts to depend solely on Honduras. Over the years Griffin management were repeatedly reminded that 
the direct cost differential was \$1 per garment and when there were management changes at their customer this prominent figure dwarfed more strategic considerations.

\subsection{Case B}

Case B, Stevensons (Stratton, Warburton and Makins, 2003) occupies a 17-acre site and is one of the largest dedicated garment dyeing facilities in Europe, combining expertise with the economies of a semi-automated plant. Garment dyeing, as the name suggests, involves dyeing garments following their manufacture in ecru (the natural colour of the yarn). The alternative is to use pre-dyed yarn in the manufacturing process. Over recent years the company has been part of the vertically integrated operations of Coats Viyella, developing colour pallets and garmentdyeing expertise in support of the exacting demands and responsive needs of major UK retailers. Manufacturing a garment in ecru effectively postpones the decision to commit to certain colours and with it the ordering of pre-dyed yarn, one of the first steps in the traditional manufacturing process. Production runs can therefore be longer and are easier to control, as there is no yarn change or adjustment to accommodate the dye related yarn properties. However, most importantly, although the ecru garments are produced in bulk the colour processing can be split, postponing the colouring of some of the batch so it can be dyed in-line with market demand later in the season. In this way the risk of having to markdown stock at the end of a season is reduced and since excess inventory losses are typically shared, both the manufacturer and the retailer have an interest in matching inventory to actual demand.

In 2001 Coats Viyella refocused its business interests around the thread business, which resulted in them selling off or closing their UK garment manufacturing capacity. At this point many of the retailers moved much of their remaining UK production overseas to low cost global suppliers and 
with it the demand for garment dyeing capacity. A management buyout in 2001 resulted in Stevensons becoming part of the Quantum Group.

By 2002 the sales revenue of the business was a third of what it was in the late 1990s and with employees down from 500 to just 100. Stevensons was still used by major retailers to develop colour pallets for their product range and where more specialists processing was required, as in the case of pigment/wash down looks or the correcting of faulty overseas dyeing, but this was not substantial and transient in nature. The survival of Stevensons was in question and they needed to rapidly reconsider how their capability could be reconfigured to support this global supply chain. With the support of the UK Industry Forum, Stevensons investigated the problems experienced further down the supply chain with markdowns and shortages in the retail outlets. In 2002 they independently surveyed ten major retail stores looking at the stock levels of various colours and sizes of garments previously dyed by Stevensons but that were now yarn dyed and manufactured overseas. The survey showed that whereas the availability of sizes was roughly in-line with predictions, there were major shortages in some colours and surpluses in others. Subsequent discussion with the retailer confirmed that the use of global suppliers was resulting in longer lead times, so obliging the retailer to commit to colour well in advance of the season and therefore limiting the retailer's ability to respond to the mismatch between forecast and demand.

The typical offshore supply lead-time is shown in Exhibit 10. 


\begin{tabular}{|c|c|}
\hline Phase & Time (Weeks) $^{\mathbf{1}}$ \\
\hline Garment shipping & 6 \\
\hline Manufacture & 6 \\
\hline Yarn shipping & 4 \\
\hline Yarn and colour work & $4-6$ \\
\hline
\end{tabular}

Exhibit 10 Typical global supply lead-time by phase

However, $30 \%$ of orders typically incur a $25 \%$ forecast error and it is common for the accuracy of forecasting to only significantly improve once demand is analysed at the start of the 12-16 week sales season.

In the case of Stevensons, postponing the dyeing process was the obvious means of avoiding uncertainty. Stevensons already had the dyeing facility but now realised they needed to invest in the additional, but not difficult finishing process that includes dyeing, label, press, examine, package and despatch. Thereby producing garments in ecru form offshore and storing them at Stevensons garments could be dyed in line with user demand and delivered to the retailer within 5 days, a target currently being achieved.

Building the ecru option into the garment design to enable postponement avoids the current demand/supply mismatches and effectively avoids the trade-offs by assigning responsive capacity only to the dye and finishing process. Whereas the move to offshore supply two years earlier induced a demand/supply mismatch, the offshore ecru supply and local finishing restores the balance and ensures both low cost and fast response. In this way product design strategies need to

\footnotetext{
${ }^{1}$ Air transport may be used to compress these lead-times but at significant additional cost
} 
not only take account of the technical needs of production but also the business needs of the market and the delivery system.

\subsection{Case C}

Case C concerns a European operation involved in the design and manufacture of industrial pumps. The site concerned produces several ranges of pumps within separate business units and was until recently serviced by an in-house foundry. The foundry produced cast casings and housings that were subsequently machined and assembled with the shaft, impeller and bearings, before being mounted on a base plate together with a motor, where required. One of the larger business units is focused around a pump range of about 40 sizes and each size might be cast in a wide range of materials.

Recent work on increasing delivery speed had resulted in typical customer lead-times of 4 weeks for bare shaft pumps and 6 weeks for motor and base plate assemblies. This time included casting, machining and assembly. The in-house foundry lead-time was reliably 4 weeks with the capability of a 48-hour response if necessary. The foundry was capable of supplying the full range of cast materials with the exception of titanium. Some casing stock was held for the higher volume mould material combinations or in utilising a minimum melt quantity.

Even with a multimillion-pound investment in the foundry, the cost of Chinese and Indian supply was $30-50 \%$ cheaper than the in-house fully absorbed cost. When the company was taken over, the decision was made the decision to close the foundry. For the next 8 months all foundry work was to be outsourced onshore, before moving the volume castings offshore to India and China. 
With the closure of the foundry the lead-time response from the various low-cost onshore suppliers typically rose from 4 to 8 weeks with reduced delivery reliability. Furthermore, the sourcing of the higher volume more standard ductile iron castings to the low cost factory in India resulted in the lead-times rising from 4 to 16 weeks including 4 weeks freight. It is also intended to move some of the sizes in stainless steal to India, but the low volume designs and material combinations will remain with onshore suppliers for the foreseeable future and produced on a make to order basis. These lower volumes represent only $25 \%$ of the pumps sales but the proportion of overall pump value and margin is significantly higher, amounting to almost $50 \%$ of the total contribution of the business unit.

In the case of the onshore suppliers, their order backlog (of which Case C's castings form a part) acts to decouple the manufacturing core from the fluctuating market demand. This backlog contributes about 6 weeks to the 8-week lead-time, and furthermore this backlog is not static and without preferential treatment contributes to poor delivery reliability. An alternative to being part of this order backlog is to provide the casting supplier with order stability by assigning a proportion of the supplier's casting capacity, therefore providing a partial level schedule. By this means it has been demonstrated the lead-times can be reduced to a more reliable 2-4 weeks. This option is strategically favourable as it supports order winning and qualifying criteria, but does come with a cost implication. The demand variation on these higher value castings will result in the need to periodically assign work otherwise destined for the low cost offshore supplier.

\section{$6 \quad$ Cross-case analysis}


In each case study the transition to offshore supply resulted in customer service being compromised. In Case A the need for duel sourcing was only accepted in the light of experiencing a serious failure to deliver with potential loss of orders. In Case B the decision to go offshore brought with it a number of sub-optimal decisions that abandoned a strategic capability widely used in the industry. Unlike Coats Viyella, the offshore suppliers did not have a strategic interest in matching demand uncertainty and supplying ecru products was not in their interest. In addition the retailers' buyers were typically measured on gross margin, which takes no account of the implications of excess inventory or shortages. Hence, the different parts of the new supply chain are encouraged to operate independently on cost grounds. One of these major retailers, however, has recently specified that offshore suppliers should offer a garment dyeing option and buyers are to be measured on net rather than gross margin. However, although the markdown prices can be used in calculating the net margin the lost sales resulting from stock-outs is more difficult to compute.

In Case $\mathrm{C}$ the purchasing function was directed to source castings based on price, but due to the focused manufacturing structure the conflict with delivery speed and reliability was widely acknowledged. The Purchasing Manager, for example, had one set of mould tools and needed to switch them between foundries to minimise costs. Ductile iron casings were cheaper from one foundry but to gain the small melt runs required for the special materials the mould tools also needed to be simultaneously at another foundry. Delivery commonly being the casualty and evidence suggested that senior management did not see these operational conflicts created by the outsourcing decision as their concern. 
It is apparent that appreciating the strategic issues in decision-making is never as transparent as cost. Therefore, when a system is redesigned, as in the case of outsourcing, the individual elements will naturally default to their local cost measures unless otherwise directed.

One way of addressing this issue would appear to be to make the trade-off implications of outsourcing decisions more explicit. Therefore, there is a need to present the implications in such a way as to enable appropriate strategies to be identified.

The modified conflict resolution diagram (CRD) provides a simple means of displaying the conflict explicitly and is used here to

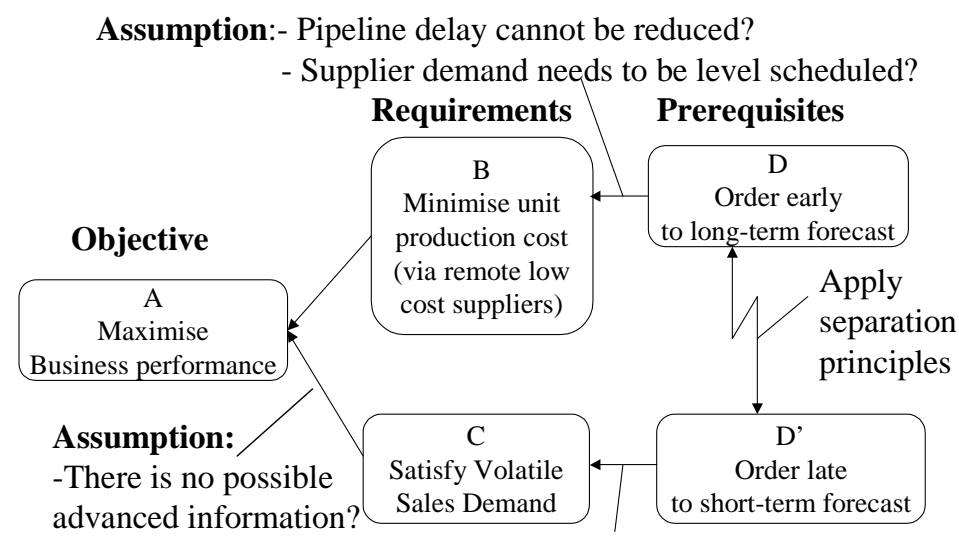

Assumption:- The resulting fluctuations cannot be effectively protected by inventory?

Exhibit 11 Generic offshore supply conflict

demonstrate an enquiry process that operationalises the three conceptual approaches identified earlier.

The common elements of the CRD, applicable to all three cases, is displayed in Exhibit 11. The conflict is explicitly defined in terms of the extended lead-time and therefore the need to order early to obtain cost benefits and late to meet market needs. The assumptions identified against the arrows illustrate the need to challenge established thinking in terms of the source of variation and how it may be managed. The TRIZ separation principles provide a means of exploring how variation and demand uncertainty may be restricted and thereby separated out. Finally, the role of inventory and capacity in managing the uncertainty and variation is implicitly reflected in the assumptions, as in DB and D'C. 
Exhibit 12 identifies how these three conceptual approaches to resolving or managing the trade-

off relate to strategy developments associated with the three cases.

\begin{tabular}{|l|l|l|l|}
\hline Case study & $\begin{array}{l}\text { Means of reducing } \\
\text { variation and uncertainty }\end{array}$ & $\begin{array}{l}\text { Separation strategies } \\
\text { (Separation Principles) }\end{array}$ & $\begin{array}{l}\text { Strategic use of capacity } \\
\text { and inventory investment }\end{array}$ \\
\hline $\begin{array}{l}\text { Case A } \\
\text { Athletic wear }\end{array}$ & $\begin{array}{l}\text { Latest sales data used early } \\
\text { in season to improve } \\
\text { forecast accuracy prior to } \\
\text { placing late order on } \\
\text { responsive supplier. }\end{array}$ & $\begin{array}{l}\text { Separate conflicting } \\
\text { requirements in time (early and } \\
\text { late ordering) and space (produce } \\
\text { in Honduras for low cost and } \\
\text { Griffin for fast response) }\end{array}$ & $\begin{array}{l}\text { 85\% of garments produced } \\
\text { by low cost Honduran supply } \\
\text { to advanced forecast and } \\
\text { held as FGI. } \\
\text { Griffin's supply (15\%) is } \\
\text { kept responsive through } \\
\text { reserving capacity and } \\
\text { holding fabric inventory. }\end{array}$ \\
\hline $\begin{array}{l}\text { Case B } \\
\text { Garment dyeing }\end{array}$ & $\begin{array}{l}\text { Offshore manufacture } \\
\text { simplified and supply lead } \\
\text { times shortened by using } \\
\text { ecru (none dyed) material as } \\
\text { standard. }\end{array}$ & $\begin{array}{l}\text { Separate conflicting } \\
\text { requirements in time (early and } \\
\text { late processing), upon condition } \\
\text { (colour), whole from the part } \\
\text { (dyeing process at end rather } \\
\text { than beginning), and space (ecru } \\
\text { garment supplied offshore, } \\
\text { finishing onshore) }\end{array}$ & $\begin{array}{l}\text { Low cost offshore supply } \\
\text { of garments in ecru } \\
\text { produced in bulk ahead of } \\
\text { demand. Invest in a } \\
\text { responsive dyeing and } \\
\text { finishing process to enable } \\
\text { a five day delivery lead } \\
\text { time. }\end{array}$ \\
\hline $\begin{array}{l}\text { Case C } \\
\text { Pump } \\
\text { manufacture }\end{array}$ & $\begin{array}{l}\text { Accelerate the casting } \\
\text { specification in the design } \\
\text { process. }\end{array}$ & $\begin{array}{l}\text { Separate offshore versus onshore } \\
\text { on condition (standard from } \\
\text { special) } \\
\text { Separate in time the release of the } \\
\text { casting specification. }\end{array}$ & $\begin{array}{l}\text { Standard castings held as } \\
\text { inventory from offshore } \\
\text { supply. Responsive } \\
\text { capacity reserved through } \\
\text { local } \\
\text { assigned capplier who has } \\
\text { responsiveness of in-house } \\
\text { foundry. }\end{array}$ \\
\hline
\end{tabular}

Exhibit 12 Cross Case Summary

$7 \quad$ Conclusions

This research has sought to better understand how strategic decision-making can be conceptually supported, with the paper specifically focusing on the strategic realignment of supply chains when being constructed around low cost global sources. Such decisions clearly exhibit trade-off 
implications that need to be acknowledged and addressed at the supply chain level. The managerial decision to use offshore supply in these three cases highlights how even proactive management decisions can overlook trade-off consequences and means of mitigation.

The research has addressed all the key research questions identified earlier, at least in part, and conceptually linked secondary sources with the cross-case analysis. The cases were chosen specifically to exemplify the impact of combining demand variation and uncertainty with extended supply lead-times associated with low cost global sourcing. The research has highlighted how and why strategies may be practically classified as means of reducing, restricting or managing variation and uncertainty, with the management being through the strategic use of capacity and inventory. The trade-off concept very effectively highlights the need to establish the potential negative strategic implications of global supply and the paper has demonstrated how the TOC and TRIZ approaches of explicitly defining the trade-off may be used in developing tailored strategies.

The additional question raised during the research concerned the role of local cost measures. In all three cases cost was a prime local measurement, which tended to drive local decision making often at the expense of responsiveness. This is exemplified in Case B by the gross margin measurement on the Buyers, and in Case $\mathrm{C}$ the need to move mould tooling between casing suppliers to minimise both supplier and tooling costs. In Case A it was evident that the less visible strategic benefits of onshore supply were constantly being weighed against the more visible cost measures, a particularly common issue raised with changes in management. This highlights the importance of the strategic implications of such global sourcing being exposed at a high enough level to enable operational strategies and measures to be aligned in support of delivery responsiveness. This research is currently being extended to address a wider range of 
industries including grocery and automotive. Further research is being planned to determine and develop the practical managerial utility of the proposed approach.

\section{References}

Adler, P.S., Goldoftas, B. and, Levine, D. I., 1999. Flexibility Versus Efficiency? A Case study

of model changeovers in the Toyota Production System. Organisation Science, 10 (1), JanuaryFebruary.

Baines, T., 2003. Strategic outsourcing for competitive manaufature. In: Proceedings of the joint international conference of EUROMA \& POMS, Como,2, p23-30.

Blackstone, J.H., and Cox, J.F., 2002. Designing unbalanced lines-understanding protective capacity and protective inventory. Production Planning and Control, 13 (4), p416-423.

Burns, T. and Stalker, G.M., 1961. The Management of Innovation, London: Tavistock.

Caputos, M., 1996. Uncertainty, flexibility and buffers in the management of the firm operating system. Production Planning and Control, 7(5), p518-528.

Conway, R., Maxwell, W., McClain, J.O, and Thomas, L.J., 1988. The role of work in progress inventory in serial production lines. Operations Research, 36(2), p229-241.

Correa, H., 1994. Linking flexibility, uncertainty and variability in manufacturing systems. Aldershot: Avebury

Da Silveira, G., and Slack, N., 2001. Exploring the trade-off concept, International Journal of Production \& Operations Management. 21 (7), p949-964.

Deming, W.E., 1982. Out of the Crisis. Cambridge, MA: MIT. 
Eisenhardt, K.M., 1989. Building Theories from Case Study Research. Academy of Management Review, 14(4), p532-550.

Feitzinger, E., and H. L. Lee, 1997. Mass customization at Hewlett-Packard: The Power of Postponement. Harvard Business Review, January-February, p116-121.

Ferdows, K. and De Meyer, A., 1990. Lasting improvements in manufacturing performance: in search of a new theory. Journal of Operations Management, 9 (2), p168-184.

Ferdows, K., 1997. Making the most of foreign factories. Harvard Business Review, MarchApril, p73-88.

Fisher, M.L., Hamond, J.H., and Obermeyer, W.R., 1994. Making supply meet demand in an uncertain world. Harvard Business Review, May-June, p83-93.

Fisher, M., Hammond, J., Obermeyer, W., and Raman, A., 1997. Configuring a supply chain to reduce the cost of demand uncertainty. Production and Operations Management, 6 (3), p211225.

Fisher, M. L., Raman, A., and McClelland, A.S., 2000. Rocket science retailing in almost here are you ready? Harvard Business Review, July-August, p115-124.

Gattorna, J.L., and Walters, D.W., 1996. Managing the Supply Chain. London: Macmillan.

Geary, S., Disney, S.M., and Towill, D.R., 2006. On bullwhip in supply chains - historical review, present practices and expected future impact. International Journal of Production Economics

Goldratt, E.M., 1983. Cost accounting: the number one enemy of productivity. Proceedings of the $26^{\text {th }}$ Annual APICS Conference, October, p 433-435.

Goldratt, E.M., and Cox, J., 1984. The Goal. USA: North River Press. 
Goldratt, E.M., and Fow, R.E, 1986. The Race. New York: North River Press.

Goldratt, E.M., 1990. The Theory of Constraints. New York: North River Press.

Goldratt, E., 1996. Production the TOC Way. USA: AGI.

Hayes, R.H., and Wheelwright, S.C., 1979. The dynamics of process-product life

cycles. Harvard Business Review, 57 (2), p127-136.

Hill, T., 1985. Manufacturing Strategy. London: Macmillan Education.

Hill,T., 2005. Operations Management: Strategic context and managerial analysis. $2^{\text {nd }}$ Ed.

Basingstoke: Macmillan Palgrave.

Hill, T., Menda, R., and Dilts, D.M., 1998. Using product profiling to illustrate

manufacturing-marketing misalignments. Interfaces, 24 (4), p47-63.

Kaplan, R.S., 1984. Yesterdays Accounting Undermines Production. Harvard

Business Review, July-August, p95-101.

Lee, H.L., 2002. Alligning Supply Chain Strategies with Product Uncertainties. California Lowson, R.H., 2003. Apparel sourcing: assessing the true operational cost. International Journal of Clothing Science and Technology, 15 (5), p0955-6222.

Mason-Jones, R., and Towill, D.R., 1997. Information enrichment: designing the supply chain for competitive advantage. Supply Chain Management, 2 (4) p137-148.

Mason-Jones, R., Naylor, J.B., and Towill, D.R., 2000. Engineering the Leagile Supply Chain. International Journal of Agile Manufacturing Systems 02 (1), p54-61.

Miles, M. B., and Huberman, A.M., 1994. Qualitative Data Analysis. $2^{\text {nd }}$ ed. London: Sage. Nair, A., and Closs, D.J., 2006. An examination of the impact of coordinating supply chain policies and price markdowns on short lifecycle product retail performance. International Journal of Production Economics ?(?), p? 
Nakane, J., 1986. Manufacturing Futures Survey in Japan, A Comparative Survey 1983-1986. Waseda University, Systems Science Institute, May, Tokyo.

Newman, W., R., Hanna, M. and Maffei, M.J., 1993. Dealing with the uncertainties of manufacturing: flexibility, buffers and integration. International Journal of Operations \& Production Management, 13 (1), p19-34.

Ohno, T., 1988. The Toyota Production System; Beyond Large-Scale Production.

Portland, OR: Productivity Press.

Salamatov, Y., 1999. TRIZ: The Right Solution At The Right Time. The Netherlands: Insytec BV.

Scheinkopf, L.J., 1999. Thinking for a change - putting the TOC thinking processes to

use. New York: St. Lucie Press.

Schmenner, R.W., and Swink, M.L., 1998. On theory in operations management.

Journal of Operations Management, 17, p97-113.

Schonberger, R.J., 1982. Japanese Manufacturing Techniques: nine hidden lessons of simplicity. New York: Free Press.

Shingo, S., 1990. Single Minute Exchange of Die. Portland, OR: Productivity Press.

Skinner, W. ,1969. Manufacturing-missing link in corporate strategy. Harvard Business Review, May-June, p136-145.

Skinner, W., 1974. The Focused Factory. Harvard Business Review, May-June, p11321

Slack, N., 1998. Generic Trade-offs and responses: an operations strategy analysis. International Journal of Business Performance Management, 1 (1), p13-27.

Stratton, R., and Mann, D., 2003. Systematic Innovation and the underlying principles behind TOC and TRIZ applied. Journal of Materials Processing Technology, 139, p120-126. 
Stratton, R. and Warburton R, 2003. The strategic integration of lean and agile supply.

International Journal of Production Economics, 85 (2), p183-198.

Stratton, R., Warburton, R.D.H., and Making, G., 2003. Managing demand uncertainty via product and process innovation. In: Proceedings of the $8^{\text {th }}$ International Symposium on Logistics, Seville, p93-98.

Van Hoek, R. I., 1998. Reconfiguring the supply chain to implement postponed Manufacturing. Int. J. of Logistics Management, 9(1)

Vastag, G. ,2000. The theory of performance frontiers. Journal of Operations

Management, 18, pp.353-360.

Yin, R.K., 1994. Case Study Research - Design and methods. $2^{\text {nd }}$ Ed., London: SAGE 